\title{
Cardiothoracic surgery educational research and training innovation: A review of 2018-2019
}

\author{
Megan F. Hunt, BS, Katherine Giuliano, MD, Eric Etchill, MD, MPH, and Stephen C. Yang, MD
}

In the era of evidence-based medicine, leaders in cardiothoracic surgery education research are advocating for rigorous education research to best advance the future of cardiothoracic surgery. ${ }^{1}$ Societies and organizations that serve the field provide an arena for advancing and discussing new research and knowledge with the ultimate goal of advancing patient care. ${ }^{2}$ We offer an overview of recent education initiatives and advances in cardiothoracic surgery, focusing on peer-reviewed published work and material presented at annual meetings during the 2018-2019 academic year. The research is presented beginning with topics in cardiothoracic surgery pertinent to medical students, then residents, then the greater community, with sections devoted to the fields of cardiac surgery and thoracic surgery.

\section{TOPICS IN CARDIOTHORACIC SURGERY EDUCATION}

\section{Medical Student Education: How to Foster Interest and Success}

General surgery and cardiothoracic surgery interest groups continue to prove effective in increasing interest in surgical fields through peer-led programming and access to faculty. ${ }^{3-5}$ Early exposure to surgery through society scholarships drastically increases the likelihood of going into a surgical field, including cardiothoracic surgery. ${ }^{6}$ This was quantified by comparing the match results of American Association for Thoracic Surgery Summer Scholars with the general medical student population, which displayed a $32 \%$ match rate into general surgery or cardiothoracic surgery compared with $8 \%$ nationally among those who did not participate in this program. $^{6}$

Further research into the success of medical students focused on performance in the general surgery clerkship.

\footnotetext{
From the Division of Thoracic Surgery, Department of Surgery, The Johns Hopkins Medical Institutions, Baltimore, Md.

Disclosures: The authors reported no conflicts of interest.

The Journal policy requires editors and reviewers to disclose conflicts of interest and to decline handling or reviewing manuscripts for which they may have a conflict of interest. The editors and reviewers of this article have no conflicts of interest.

Received for publication Feb 18, 2020; revisions received March 18, 2020; accepted for publication April 3, 2020; available ahead of print April 23, 2020.

Address for reprints: Megan F. Hunt, BS, Division of Thoracic Surgery, Department of Surgery, The Johns Hopkins Medical Institutions, 600 N Wolfe St, Blalock 240, Baltimore, MD 21287 (E-mail: mhunt25@jhmi.edu).

J Thorac Cardiovasc Surg 2020;160:1133-7

$0022-5223 / \$ 36.00$

Copyright (c) 2020 by The American Association for Thoracic Surgery

https://doi.org/10.1016/j.jtcvs.2020.04.049
}

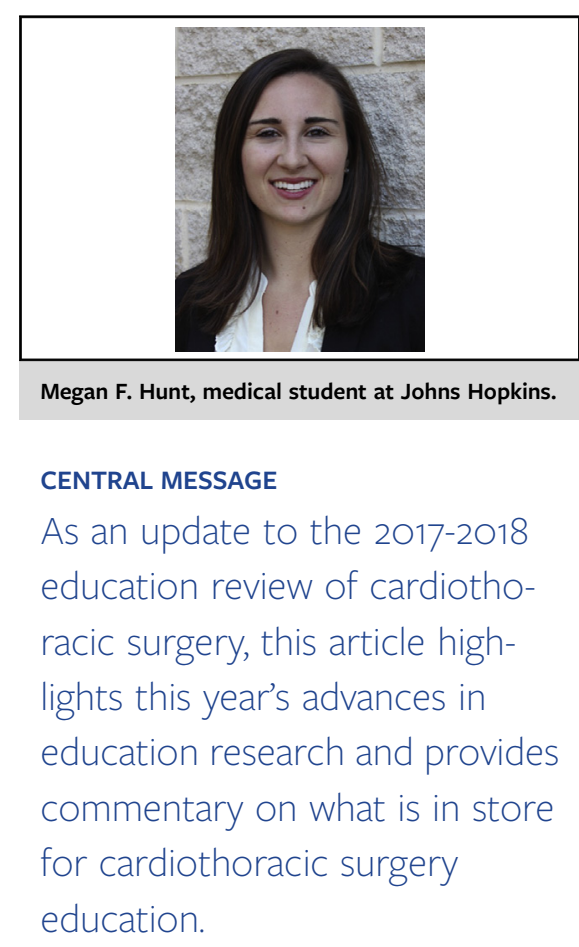

\section{PERSPECTIVE}

Much research into education within the field of cardiothoracic surgery occurred during the 20182019 academic year. Robust sessions provided highlights at cardiothoracic surgery-related annual meetings demonstrating that it has again been an exciting year for the field. Advances in education are critical to the development of this specialty and will form the core of future cardiothoracic surgery education.

See Commentaries on pages 1138 and 1139.

Results indicated that using multiple, varied resources to study for the National Board of Medical Examiners exam with increased study time closer to the exam resulted in better scores. ${ }^{7}$ Overall performance on the surgical clerkship is important, because earning a High Pass or Honors was the only factor that correlated with matching into a surgical residency. ${ }^{8}$ Using these data to aid students, medical schools should continue to foster the development of surgical interest groups, specifically with access to faculty early in medical school and within the surgical rotation. Support should also include evidence-based National Board of Medical Examiners study strategies. 


\section{Residency Training: Pitfalls in Education}

In recent years, residency education has trended toward earlier specialization for those sure of their interests. This topic was discussed in detail last year. ${ }^{9}$ The key highlights include that integrated residency was more popular amongst those interested in a cardiac surgery career, traditional and $4 / 3$ residencies were more popular amongst future thoracic surgeons, and that integrated programs offered lower general surgery case volumes. ${ }^{9}$ In amalgamating research from this year, the field continues to see increasing numbers of integrated training programs, in which trainees apply and matriculate directly into cardiothoracic surgery-specific training programs in lieu of the traditional general surgery residency followed by cardiothoracic surgery fellowship. Concomitantly, there have been increasing trends toward further subspecialization within cardiothoracic surgery, with many practicing either cardiac surgery or thoracic surgery, rather than both. Several studies have raised questions about this training model. When comparing integrated cardiothoracic surgery program graduates who went on to practice combined cardiothoracic surgery versus those who went into primarily cardiac or thoracic surgery, those who practiced combined cardiothoracic surgery were more likely to report excellent preparation for qualifying examinations than those who subspecialized. Subspecialization led to self-reported perceived deficiencies in respondents' nonspecialty areas. ${ }^{10}$

The move toward integrated cardiothoracic surgery training programs also has potential influence on traditional general surgery trainees. One study found that, among general surgery residents-even in senior residents with higher case volumes - there remained a lack of comfort in performing thoracic procedures, particularly lobectomies. ${ }^{11}$ Residency curricula should continue to emphasize general surgery trainees' exposure to thoracic surgeries. If adequate exposure is not obtained such that trainees continue to be uncomfortable, then this study would advise programs to prevent nonfellowship-trained residents from performing a lobectomy. ${ }^{11}$ A review of the Accreditation Council for Graduate Medical Education operative log reports for general surgery residents from 1990 to 2018 shows that first assistant cases have decreased from $21.8 \%$ of total operative experience in 1990 to $2.5 \%$ in $2018 .^{12}$ Teaching assistant cases have also dropped, from $7.4 \%$ in 1990 to $3.5 \%$ in 2018 , although there has been a slight recent uptrend since $2010 .{ }^{12}$ With such self-reported data, it is prudent to consider that residents may be inaccurately reporting their role in the surgery or that assistant surgeries fail to be reported because they do not contribute to graduation requirements. However, educators should consider that trends are moving toward more active, teaching assistant case-based training modes. To accommodate, programs should continue to encourage appropriate technical autonomy and decision making.
Researchers have sought to understand how burnout affects residents and ways to safeguard from burnout. Traditional markers of resident evaluation and progress-US Medical Licensing Examination scores, American Board of Surgery In-Training Examination percentile, or surgical milestones were not shown to correlate with burnout. ${ }^{13}$ One study, however, demonstrated that mean global emotional intelligence (EI) was lower in residents who reported burnout, as defined by high emotional exhaustion, high depersonalization, and low sense of personal accomplishment. ${ }^{13}$ Alternative metrics assessing EI, such as the trait EI questionnaire and Maslach Burnout Inventory, are needed to adequately assess resident burnout. With accurate measurement, active programing can be instated to prevent and address burnout. Propensity for burnout can be mitigated by utilizing 6 different habits: sleep, exercise, meditation, gratitude, self-compassion, and connection. ${ }^{14}$ By integrating these habits, trainees and physicians can form a so-called resilience bank account to optimize their clinical performance. $^{14}$

Hidden biases and mistreatment are also emerging on the forefront of research in cardiothoracic surgery similar to other fields of medicine. Sexual harassment in cardiothoracic surgery was assessed through a survey distributed to the Society of Thoracic Surgeons, Women in Thoracic Surgery, and Thoracic Surgery Residents Association listservs. ${ }^{15}$ The results indicated that all levels of trainingmedical students to surgeons-were affected. Among attending surgeons, $81 \%$ of women and $46 \%$ of men had experienced harassment. ${ }^{15}$ Unconscious biases were also present within surgical education. Although stereotyped pattern recognition is important to the development of clinical acumen and operational skills, it harms the training process when people are not aware of their own hidden biases. ${ }^{16}$ Applicant selection, perception of trainees, and patient care can all be negatively affected by unconscious biases. Training programs should create policies to combat potential biases and promote a culture of diversity and inclusion. $^{16}$

Several articles this year discussed the importance of deliberate practice outside of operating rooms. The see 1 , do 1 , teach 1 mantra should be modified to include the importance of practice at each stage of skill acquisition. ${ }^{17,18}$ To do this, the field must continue to embrace practice as a core part of training, encourage creation of personal or institutional drills, and develop systems for coaching and measuring trainee progress. ${ }^{18}$ There has been debate concerning the influence of fatigue on resident performance in training simulations, yet a study of pre- and postcall resident acquisition of robot simulator skills demonstrated no difference in overall scores and time to completion. ${ }^{19}$ This suggests that residents should implement practice when feasible. 
Simulation is an increasingly studied modality for practicing cardiothoracic surgery and should continue to be researched to provide optimal resident and surgeon development. ${ }^{9}$ Although surgical simulators have been criticized by some for not being high-fidelity, today's evolved and varied simulations can be used to practice rare events and difficult cases, improve patient safety, and augment team performance and confidence. ${ }^{20-22}$

Another area of research regarding modes of practice pertains to the role of mock oral examinations in preparation for certifying exams. One study examined the implementation of biannual mock oral examinations and found that participants gradually improved over the course of the study and then achieved a $100 \%$ pass rate on the certifying exam. Despite the labor-intensive nature of designing and administering mock oral examinations, the authors concluded that the mock exams were a useful education adjunct to both assess and prepare trainees for their certifying examination. ${ }^{23}$

Regarding cardiothoracic residency accreditation, the Accreditation Council for Graduate Medical Education laid a foundation to have the milestones revised for all medical specialties beginning in 2018. For thoracic surgery, a committee representing the stakeholders (American Board of Thoracic Surgery, Thoracic Surgery Directors Association, Thoracic Surgery Residents Association, and other volunteers) was convened to begin the second rendition, to be known as Milestones 2.0. The individual milestones representing the core competencies for medical knowledge and patient care were simplified, and common language was drafted for all specialties in the other areas of systems-based practice, practice-based learning and improvement, professionalism, and interpersonal and communication skills. A brief review of this process and documentation is summarized by Mitzman and collegues. ${ }^{24}$ Implementation for all Accreditation Council for Graduate Medical Education accredited training programs will begin in July 2020.

\section{Social Media Connects Attendings and Students}

The establishment of the Thoracic Surgery Social Media Network, a collaboration of leading cardiothoracic surgery journals to highlight publications over social media, has led to the dissemination of literature to a larger audience and is an avenue for trainee tweet-based journal clubs. ${ }^{25,26}$ The benefits of this practice include rapid dissemination of information, establishing a brand, cataloging educational take-home points, providing education experiences to those not at the conference or session, and opportunities for networking and mentorship. ${ }^{27}$ Caution must be taken when using social media to ensure that posts remain professional, anonymous (regarding patient information), accurate, and within the bounds of medical ethics and approved research practices. ${ }^{28}$ Social media will only become more present; thus, research into improving its use and effectiveness in cardiothoracic surgery is timely and uniquely important.

\section{Cardiac Surgery Education Research}

Researchers are developing simulators aimed at augmenting skill acquisition outside of operating rooms specifically for the wide variety of cardiac surgery procedures. A high-fidelity minimally invasive mitral valve surgery (MIMVS) simulator has been developed for endoscopic and robotic procedure training. Appropriate width and depth equations were developed to calibrate the 4 cameras within the simulator; using this model, 99 surgeons validated that this model would be useful for training in MIMVS with suture placement that felt realistic. ${ }^{29}$ The MIMVS simulator technology has the potential to be valuable for skills acquisition and assessment going forward, but at the moment requires more validation to demonstrate its reproducibility in operating rooms and effectiveness in improving patient outcomes. ${ }^{30}$

A saphenous vein harvest model is another simulator that is in the early stages of development. ${ }^{31}$ Performance ratings have shown that it could reliably indicate skill level, because those with higher levels of experience performed slightly better than those with less experience. ${ }^{31}$ Further work is needed to ensure that skills are appropriately transferrable to practice. The Ramphal cardiac surgery simulator was modified to simulate cardiac transplantation beginning at the stage of surgery following removal of the native diseased heart. ${ }^{32}$ This technology allows for repetitive practice due to the ability to replace component parts, provides the opportunity to practice individual steps of the operation, and incorporates adverse event training. ${ }^{32}$ Concerning all cardiac simulation models, there remains a need to ensure that these measures translate to actual performance in operating rooms and improved patient outcomes. ${ }^{33}$

One study evaluated a cardiac surgery trainee's ability to perform so-called skin-to-skin operations, including coronary artery bypass grafting cases and/or valve replacements by assessing whether they successfully performed defined critical steps in the operation, compared with a single, attending surgeon. In this study, the patients within the cohort where trainees conducted the operation had no difference in postoperative death or major morbidity, although there was a slightly higher readmission rates compared with those in the attending surgeon cohort. ${ }^{34}$ Similar favorable results, with better-than-expected outcomes in traineeperformed cases, were seen in a study measuring the learning curves of cardiac surgery trainees. When including coronary artery bypass grafting cases and/or valve operations in the Society of Thoracic Surgeons database, the resident learning curve shows a small increase in adverse events peaking at 70 cases then immediately declining and leveling out at 140 cases. ${ }^{35}$ No individual resident was associated with overall mortality or any major morbidity. ${ }^{35}$ With these 
outcomes, academic programs should continue to provide trainees with experience as the primary operative surgeon.

Satisfaction of cardiac surgery trainees is another area of interest. A study based in the United Kingdom indicated that national trainees are satisfied with clinical and education supervision (both during hours and outside of work hours), but they remain dissatisfied with the workload. ${ }^{36}$ Although nationally there were trends toward better overall satisfaction, the researchers encourage individual hospitals to perform trainee-specific analysis of satisfaction and dissatisfaction to improve their programs. ${ }^{36}$

Collaborative learning models, or team approaches to learning, were studied in the field of pediatric cardiac care. Leveraging others' experience in learning intensifies and expedites the learning process, especially in regard to newly implemented techniques and best practices. ${ }^{37}$ By implementing learning in a collaborative setting, training could better reflect the real challenges of an operating room, which involves many different disciplines outside of cardiac surgery.

\section{Thoracic Surgery Education Research}

With segmentectomy becoming increasingly common for early lung cancer and benign lesions, examination of the learning curves for these procedures is particularly relevant. For video-assisted thoracic surgery (VATS) segmentectomy, the inflection point for the learning curve, where the operating surgeon transitioned from phase 2 (increased competence phase) to phase 3 (highest skill phase) was identified at 84 cases; this was determined based on operative time and the cumulative sum value of operative time in all cases. ${ }^{38}$ The learning curve for robotic segmentectomy was also divided into 3 phases, with technical competency determined to occur in the second phase during the 40th case. ${ }^{39}$ Operative time and blood loss tended to decrease after phase 1 , the initial learning phase.

Another subject of extensive research is VATS lobectomy, especially in regard to validation of the VATS Assessment Tool (VATSAT), a novel assessment tool for surgical technique. Virtual reality filming of individuals of varying skill levels provided validity evidence for VATSAT according to unitary framework. ${ }^{40}$ Experts in VATS also validated the VATSAT tool using the Delphi method. ${ }^{41}$ The VATSAT provides procedure-specific training and feedback to better prepare trainees and young surgeons to perform VATS unsupervised. ${ }^{41,42}$

Endoscopy is an important skill for thoracic surgery residents. Because the Fundamentals of Endoscopic Surgery (FES) exam is required during residency, it is recommended that residents do at least 15 minutes of training per week to improve proficiency. ${ }^{43}$ The FES performance exam initially revealed higher scores for men than women, but through the use of task-specific simulation-based mastery learning, gender-based difference in pass rates were eliminated. ${ }^{44}$
Other methods for improving FES exam performance include a dedicated curriculum for residents developed by endoscopy experts from FES online didactics and training cases from the GI Mentor II simulator. ${ }^{45}$ In this curriculum, residents were required to complete online didactics and achieve expert performance twice on simulator cases. ${ }^{45}$

To better understand how to improve thoracic training programs in the United States, training was compared with residencies in Canada. Although there were many areas studied, results regarding resident education demonstrated that simulation training is more common in the United States, whereas an annual 4-day national bootcamp is unique to Canada. ${ }^{46}$ The bootcamp course consists of lecture and animal-model sessions aimed at teaching key foundational procedures within thoracic surgery. It was developed over 3 years in response to needs-assessments and resident survey data. ${ }^{47}$ The response to the course has been overwhelmingly positive, although annual modifications continue to be made for further improvement. Continuing to integrate educational opportunities will serve current and future trainees well as thoracic surgery is met with further technologic advances.

\section{CONCLUSIONS}

There have been significant and exciting advances in the field of cardiothoracic surgery education in the 2018-2019 academic year. This is not an exhaustive list of the topics studied during this time, but we aimed to provide some highlights and updates. Developing and validating simulation technologies, establishing reproducible learning curves, and improving the medical student surgical clerkship experience were particularly popular topics this year. Innovations that bolster training programs are of high interest. With programs and surgeons instituting the new techniques and methods, it is clear that research-based education will positively influence the training of future medical students, residents, and faculty. Continued investment in educational research, validation of training techniques, and development of training tools and curricula will continue to advance cardiothoracic surgery.

\section{References}

1. Weston JA, David EA. Cardiothoracic surgical education research is NOT for dabblers anymore. J Thorac Cardiovasc Surg. 2019;157:829.

2. Dearani JA, Rosengart TK, Marshall MB, Mack MJ, Jones DR, Prager RL, et al. Incorporating innovation and new technology into cardiothoracic surgery. Ann Thorac Surg. 2019;107:1267-74.

3. Gallagher KC, Matevish LE, Neuzil K, Evans PT, Eastham SC, Terhune KP, et al. Peer-led surgical clerkship programming support through the general surgery interest group at the Vanderbilt University school of medicine. J Surg Educ. 2019; 76:1451-5.

4. Davis TA, Yesantharao PX, Yang SC. Where do we begin: building blocks to establish a cardiothoracic surgery interest group. Presented at: Society of Thoracic Surgeons 54th Annual Meeting; January 27-31, 2018; Fort Lauderdale, FL.

5. Dabal R, Garner E, Burns Z, Porterfield J, Mauchley D, Cleveland D, et al. Cardiothoracic surgery interest in surgical residency applicants. Presented at: Southern Thoracic Surgical Association 66th Annual Meeting; November 6-9, 2019; Marco Island, FL. 
6. Rushing GD, D'Souza D, Ferguson C, Way D, Higgins RSD, Moffatt-Bruce $\mathrm{SD}$, et al. Does early exposure to general surgery and cardiothoracic surgery help with recruiting? Presented at: 99th Annual Meeting of The American Association for Thoracic Surgery; May 4-7, 2019; Toronto, Ontario, Canada.

7. Volk AS, Rhudy AK, Marturano MN, Ott L, DuCoin C. Best study strategy for the NBME clinical science surgery exam. J Surg Educ. 2019;76: $1539-45$.

8. Schuman AD, Heisel CJ, Black KM, Matusko N, Gilbert CM, James CL, et al. Student factors that influence clerkship grades and matching into a surgical residency. J Surg Educ. 2019;76:393-400.

9. Hunt MF, Zhou X, Lui C, Yang SC. Educational research and training innovation in cardiothoracic surgery: a year in review. J Thorac Cardiovasc Surg. 2019;157: 1722-7.

10. Antonoff MB, Luc JGY, Patterson GA, Meyers BF, Damiano RJ Jr, Moon MR. Graduate subspecialty and perceptions of cardiothoracic surgery training: a 60year retrospective study. Ann Thorac Surg. 2019;107:285-93.

11. DeBoard ZM, Paisley M, Thomas DD. Self-appraised readiness of senior and graduating general surgery residents to perform thoracic surgery. J Surg Educ. 2018;75:877-83.

12. Cortez AR, Winer LK, Kassam A-F, Hanseman DJ, Kuethe JW, Quillin RC III, et al. See none, do some, teach none: an analysis of the contemporary operative experience as nonprimary surgeon. J Surg Educ. 2019;76:e92-101.

13. Cofer KD, Hollis RH, Goss L, Morris MS, Porterfield JR, Chu DI. Burnout is associated with emotional intelligence but not traditional job performance measurements in surgical residents. J Surg Educ. 2018;75:1171-9.

14. Maddaus M. The resilience bank account: skills for optimal performance. Ann Thorac Surg. 2020;109:18-25.

15. Ceppa DP, Dolejs SC, Boden N, Phelan S, Yost KJ, Donington J, et al. Sexual harassment and cardiothoracic surgery:\# UsToo? Ann Thorac Surg. 2020;109: 1283-8.

16. Backhus LM, Lui NS, Cooke DT, Bush EL, Enumah Z, Higgins R. Unconscious bias: addressing the hidden impact on surgical education. Thorac Surg Clin. 2019;29:259-67.

17. Dearani JA, Stulak JM. In surgical training, practice makes—almost—perfect. J Thorac Cardiovasc Surg. 2019;158:e15-6.

18. Han JJ, Patrick WL. See one, practice, do one, practice, teach one, practice: the importance of practicing outside of the operating room in surgical training. $J$ Thorac Cardiovasc Surg. 2019;157:671-7.

19. Robison W, Patel SK, Mehta A, Senkowski T, Allen J, Shaw E, et al. Can fatigue affect acquisition of new surgical skills? A prospective trial of pre- and post-call general surgery residents using the da Vinci surgical skills simulator. Surg Endosc. 2018;32:1389-96

20. Carpenter AJ. Simulation is a valuable tool for team training. J Thorac Cardiovasc Surg. 2018;155:2525.

21. Helder MRK, Stulak JM. High-fidelity simulation: making hard to teach cases teachable. J Thorac Cardiovasc Surg. 2018;156:1137-8.

22. Merritt-Genore HL, Zavala R, Brakke T. Interprofessional simulation in cardiothoracic surgery improves team confidence. Presented at: Annual Meeting of The Society of Thoracic Surgeons; January 27-29, 2019; San Diego, CA.

23. Corsini E, Mitchell KG, Nguyen TC, Vaporciyan AA. Role of mock oral examinations in cardiothoracic surgery training. Presented at: Annual Meeting of The Society of Thoracic Surgeons; January 27-29, 2019; San Diego, CA.

24. Mitzman B, Beller JP, Edgar L. Thoracic surgery milestones 2.0: rationale and revision. J Thorac Cardiovasc Surg. March 31, 2020 [Epub ahead of print].

25. Luc JGY, Archer MA, Arora RC, Bender EM, Blitz A, Cooke DT, et al. Social media improves cardiothoracic surgery literature dissemination: results of a randomized trial. Ann Thorac Surg. 2020;109:589-95.

26. Ni Hici T, Archer M, Harrington C, Luc JGY, Antonoff MB. Trainee thoracic surgery social media network: early experience with tweetchat-based journal clubs. Ann Thorac Surg. 2019;109:285-90.

27. Luc JGY, Antonoff MB. Live tweet the Society of Thoracic Surgeons annual meeting: how to leverage twitter to maximize your conference experience. Ann Thorac Surg. 2018;106:1597-601.
28. Varghese TK Jr, Entwistle JW III, Mayer JE, Moffatt-Bruce SD, Sade RM Cardiothoracic Ethics Forum. Ethical standards for cardiothoracic surgeons participation in social media. Ann Thorac Surg. 2019;108:666-70.

29. Sardari Nia P, Daemen JHT, Maessen JG. Development of a high-fidelity minimally invasive mitral valve surgery simulator. J Thorac Cardiovasc Surg. 2019; $157: 1567-74$

30. Choe G, Tibayan FA. Commentary: have mitral valve simulators made it to reality? J Thorac Cardiovasc Surg. 2019;157:1576.

31. Duffy MC, Ibrahim M, Lachapelle K. Development of a saphenous vein harves model for simulation-based assessment. J Thorac Cardiovasc Surg. 2019;157: 1082-9.

32. Wilson HH, Caranasos TG, Heathcote SA. A high-fidelity, tissue-based simulation for cardiac transplantation. Presented at: Annual Meeting of The Society of Thoracic Surgeons; January 27-29, 2019; San Diego, CA

33. Yanagawa B, Ribeiro R, Naqib F, Fann J, Verma S, Puskas JD. See one, simulate many, do one, teach one: cardiac surgical simulation. Curr Opin Cardiol. 2019 34:571-7.

34. Bloom JP, Heng E, Auchincloss HG, Melnitchouk SI, D’Alessandro DA, Villavicencio MA, et al. Cardiac surgery trainees as "skin-to-skin" operating surgeons: midterm outcomes. Ann Thorac Surg. 2019;108:262-7.

35. Krebs ED, Hawkins RB, Beller JP, Mehaffey JH, Chancellor WZ, Teman NR, et al. Objective measure of learning curves for trainees in cardiac surgery. Presented at: 99th Annual Meeting of The American Association for Thoracic Surgery; May 4-7, 2019; Toronto, Ontario, Canada.

36. Chan J, Oo S, Yeatman M. Is there a national variation in cardiothoracic trainees' satisfaction? Evaluation of the United Kingdom general medical council national training surveys. J Card Surg. 2019;34:1069-74.

37. Karamlou T, Rao R, Najm H. Collaborative learning models in pediatric cardiac care: the continuum of learning and positive change through shared inquiry. Ann Thorac Surg. 2019;107:1293-6.

38. Hamada A, Oizumi H, Kato H, Suzuki J, Nakahashi K, Sho R, et al. Learning curve for port-access thoracoscopic anatomic lung segmentectomy. J Thorac Cardiovasc Surg. 2018;156:1995-2003.

39. Zhang Y, Liu S, Han Y, Xiang J, Cerfolio RJ, Li H. Robotic anatomical segmentectomy: an analysis of the learning curve. Ann Thorac Surg. 2019;107: $1515-22$.

40. Jensen K, Hansen HJ, Petersen RH, Neckelmann K, Vad H, Møller LB, et al Evaluating competency in video-assisted thoracoscopic surgery (VATS) lobectomy performance using a novel assessment tool and virtual reality simulation. Surg Endosc. 2019;33:1465-73.

41. Jensen K, Petersen RH, Hansen HJ, Walker W, Pedersen JH, Konge L. A novel assessment tool for evaluating competence in video-assisted thoracoscopic surgery lobectomy. Surg Endosc. 2018;32:4173-82.

42. Mahajan NN, Blackmon SH. Can a tool assess whether young thoracic surgeons are competent to perform video-assisted thoracoscopic lobectomy? J Thorac Cardiovasc Surg. 2019;158:e23-4.

43. Li M, Lee SN, Tantawy MM, Rao SR, Suzuki KN. Role of esophagogastroduodenoscopy simulation in general surgery residency education. Presented at: Annual Meeting of The Society of Thoracic Surgeons; January 27-29, 2019; San Diego, CA.

44. Ritter EM, Lineberry M, Hashimoto DA, Gee D, Guzzetta AA, Scott DJ, et al. Simulation-based mastery learning significantly reduces gender differences on the fundamentals of endoscopic surgery performance exam. Surg Endosc. 2018;32:5006-11.

45. Mizota T, Anton NE, Huffman EM, Guzman MJ, Lane F, Choi JN, et al Development of a fundamentals of endoscopic surgery proficiency-based skills curriculum for general surgery residents. Surg Endosc. 2020;34:771-8.

46. Schieman C, Seder CW, D'Amico TA, Grondin SC. General thoracic surgical training in North America: contrasting general thoracic surgery residencies in Canada and the United States. J Thorac Cardiovasc Surg. 2018; 156:2379-87.

47. Schieman C, Ujiie H, Donahoe L, Hanna W, Malthaner R, Turner S, et al. Developing a national, simulation-based, surgical skills bootcamp in general thoracic surgery. J Surg Educ. 2018;75:1106-12. 